Research Paper

\title{
Direct differentiation of insulin-producing cells from human urine-derived stem cells
}

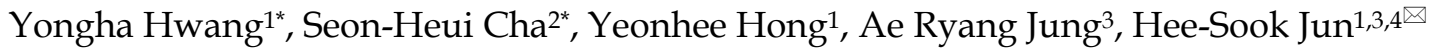 \\ 1. College of Pharmacy and Gachon Institute of Pharmaceutical Science, Gachon University, Incheon, 21999, Republic of Korea \\ 2. Department of Marine Bioindustry, Hanseo University, Chungcheongman-do, 31962, Republic of Korea \\ 3. Lee Gil Ya Cancer and Diabetes Institute, Gachon University, Incheon, 21936, Republic of Korea \\ 4. Gachon Medical Research Institute, Gil Hospital, Incheon, 21999, Republic of Korea \\ *These authors contributed equally to this work. \\ $\square$ Corresponding author: Hee-Sook Jun, Ph.D., Lee Gil Ya Cancer and Diabetes Institute, Gachon University, 7-45 Sondo-dong, Yeonsu-ku, Incheon 21999, \\ Republic of Korea. Tel: +82-32-899-6056; Fax: +82-32-899-6057; E-mail: hsjun@gachon.ac.kr.
}

(1) The author(s). This is an open access article distributed under the terms of the Creative Commons Attribution License (https://creativecommons.org/licenses/by/4.0/). See http://ivyspring.com/terms for full terms and conditions.

Received: 2019.04.24; Accepted: 2019.10.09; Published: 2019.11.15

\begin{abstract}
The loss of pancreatic $\beta$-cells is a cause of diabetes. Therefore, replacement of pancreatic $\beta$-cells is a logical strategy for the treatment of diabetes, and the generation of insulin-producing cells (IPCs) from stem cells has been widely investigated as an alternative source for pancreatic $\beta$-cells. Here, we isolated stem cells from human urine and investigated their differentiation potential into IPCs. We checked the expression of surface stem cell markers and stem cell transcription factors, and found that the isolated human urine-derived stem cells (hUDSCs) expressed the stem cell markers CD44, CD90, CD105 and stage-specific embryonic antigen (SSEA)-4. In addition, these cells expressed octamer binding transcription factor (Oct) 4 and vimentin. hUDSCs could differentiate into adipocytes and osteocytes, as evidenced by Oil-red $\mathrm{O}$ staining and Alizarin Red S-staining of differentiated cells, respectively. When we directly differentiated hUDSCs into IPCs, the differentiated cells expressed mRNA for pancreatic transcription factors such as neurogenin (Ngn)3 and pancreatic and duodenal homeobox (Pdx) 1 . Differentiated IPCs expressed insulin and glucagon mRNA and protein, and these IPCs also secreted insulin in response to glucose stimulation. In conclusion, we found that hUDSCs can be directly differentiated into IPCs, which secrete insulin in response to glucose.
\end{abstract}

Key words: urine-derived stem cell, diabetes, differentiation of insulin producing cell, pancreatic beta-cell

\section{Introduction}

Human stem cells have been of growing interest for in vitro models, disease modeling, and cell-based therapy. As there are significant differences between animal and human physiology, a translation to human biology is sometimes inadequate. Therefore, human stem cells are attractive for better models of human disease and drug reactions than animal models. In addition, stem cells have potential for tissue repair and regeneration.

Diabetes mellitus (DM) is a chronic metabolic disorder characterized by a relative or absolute deficiency in circulating insulin levels, resulting in high blood sugar levels over a prolonged period [1-3].
Pancreatic $\beta$-cell loss is known to be a major cause of both type 1 and type 2 diabetes [4]. Therefore, restoration of insulin-producing $\beta$-cells would be a logical strategy for the treatment of both forms of diabetes. Insulin therapy has been used to treat diabetes, but it can have side effects such as hypoglycemic episodes. Islet transplantation is an effective therapy for treating severe type 1 diabetes [5], but there are limitations due to a lack of donors of islet sources [6]. In this regard, differentiated insulin-producing cells (IPCs) using human stem cells are an attractive source of alternative pancreatic islets for transplantation [7]. In addition, a consistent source 
of differentiated $\beta$-cells from human stem cells would provide a unique and valuable drug discovery platform for diabetes, and could also replace for in vitro or in vivo model systems [8,9].

Human urine-derived stem cells (hUDSCs) have advantages, including the easy and inexpensive isolation procedure [10]. They can also differentiate into various types of cells, such as adipocytes, osteocytes, chondrocytes, myocytes, and neurons [11-13]. However, the differentiation of hUDSCs into IPCs has not been investigated. Therefore, in this study, we isolated hUDSCs according to a previous report, and their potential for use as stem cells was confirmed in accordance with existing reports $[12,14]$. Finally, we confirmed that isolated hUDSCs are capable of differentiating into insulin-producing $\beta$-cells and suitable for use in the treatment of diabetes.

\section{Materials and Methods}

\section{Ethical approval}

The protocol for the collection of urine samples from healthy donors and the isolation of stem cells from urine was reviewed and approved by the Public Institutional Review Board designated by the Ministry of Health and Welfare, Korea (P01-201507-31-002).

\section{Isolation of stem cells from human urine (hUDSCs)}

To isolate stem cells from urine, fresh urine samples (average amount of $50 \mathrm{ml}$ per sample, four subjects) were immediately transferred to the laboratory under sterile conditions at $4^{\circ} \mathrm{C}$. Each sample was centrifuged at $500 \times \mathrm{g}$ for 5 minutes and the cell pellets were gently resuspended in sterile phosphate buffer saline (PBS) solution. After the cell suspension was centrifuged at $500 \times \mathrm{g}$ for 5 minutes, the cell pellets were resuspended in $3 \mathrm{ml}$ of medium composed of 1:1 mixture of DMEM/F12 (ThermoFisher Scientific, MA, USA) and keratinocyte serum free medium (KSFM, ThermoFisher Scientific), containing $5 \%$ fetal bovine serum (FBS; ThermoFisher Scientific) and 1\% penicillin/streptomycin (Welgene, Deagu, Korea). The cells were seeded $(1 \times 104$ cells/well) to 24-well plates (Falcon, USA), and incubated at $37^{\circ} \mathrm{C}$ in a $5 \% \mathrm{CO} 2$ and air humidified incubator (Heraeus HeraCell 150, Thermo). Culture medium was changed every two days until the cells formed colonies. Each colony was transferred to individual wells of 24-well plate and cultured. The cells were split when they reached 70-80\% confluency.

\section{Cell culture}

hUDSCs or human adipose tissue-derived stem cells (hADSCs; Invitrogen, USA) were seeded at $1 \times 10^{4}$ cells/well in 6-well culture plates. hUDSCs were maintained in DMEM/F12:keratinocyte SFM (1:1, $\mathrm{v} / \mathrm{v}$, ThermoFisher Scientific) medium containing $5 \%$ FBS (ThermoFisher Scientific), 1\% penicillin/streptomycin. hADSC were maintained in MesenPRO medium (Invitrogen) containing supplement, 1\% penicillin/streptomycin and 1× GlutaMAX (ThermoFisher Scientific, MA, USA). The cells were incubated in a humidified incubator with $5 \% \mathrm{CO}_{2}$.

\section{Flow cytometry}

To check the expression of stem cell markers on the surface, the cells at passage 3 were harvested and fixed with $70 \% \mathrm{EtOH}$ overnight at $4^{\circ} \mathrm{C}$. After washing twice with PBS, cells $\left(5 \times 10^{5}\right.$ cells) were stained with antibodies against FITC fluorescence-conjugated anti-CD31, anti-CD34, anti-CD44, anti-CD90, antiCD105, or anti-SSEA-4 antibodies (BD Pharmingen, USA) for $1 \mathrm{~h}$ at room temperature. Cells were washed twice with PBS and analyzed on a BD LSR II Flow Cytometer (BD Biosciences, USA).

\section{Immunocytochemical staining}

hUDSCs or hADSCs were cultured on coverslips, washed with PBS and fixed with $4 \%$ paraformaldehyde (Biosesang, Korea) for 10 minutes at room temperature. Following fixation, the cells were washed with PBS and then blocked with PBS, containing $1 \%$ bovine serum albumin (BSA) and $0.1 \%$ Triton X-100, for 30 minutes at room temperature, and incubated overnight with anti-vimentin, anti-Ecadherin, or anti-oct4 (Santa Cruz Biotechnology, Inc., USA) antibodies in a humidified chamber at $4^{\circ} \mathrm{C}$. The cells were then incubated with fluorescein-conjugated secondary antibodies (Life technology, USA) and 4',6-diamidino-2-phenylindole (DAPI) (Sigma-Aldrich, MO, USA) for $1 \mathrm{~h}$, in the dark, at room temperature. Following this, the coverslips were mounted with fluorescence mounting medium (DAKO, CA, USA) and cell images were observed under a confocal microscope (Zeiss, Germany).

\section{Adipogenic and osteogenic differentiation}

The cells were seeded $\left(1.5 \times 10^{5}\right.$ cells/well in 6-well plate) in keratinocyte SFM:DMEM/F12 (1:1) medium, containing 5\% FBS, and cultured for 1 day. The next day, the cells were incubated with adipogenic or osteogenic differentiation medium. For adipogenic differentiation, hUDSCs were incubated with DMEM, containing 10\% FBS, 1\% penicillin/ streptomycin, $1 \mu \mathrm{M}$ dexamethasone (Sigma-Aldrich), 500 M 3-isobutyl-1-methylxanthine (IBMX; Sigma- 
Aldrich, MO, USA), $5 \mu \mathrm{g} / \mathrm{ml}$ insulin (Sigma-Aldrich) and $10 \mu \mathrm{M}$ rosiglitazone (Cayman chemical, USA) for 24 days. The medium were changed every 3 days. After differentiation, cells were fixed using $4 \%$ paraformaldehyde and stained with Oil-red-O (Sigma-Aldrich). For osteogenic differentiation, one day after seeding, hUDSCs $\left(1.5 \times 10^{5}\right.$ cells/well in a 6-well plate) were incubated in DMEM, containing $10 \%$ FBS, $1 \%$ penicillin/streptomycin, $0.1 \mu \mathrm{M}$ dexamethasone, $50 \mu \mathrm{M}$ ascorbate-2-phosphate (SigmaAldrich), and $10 \mathrm{mM} \beta$-glycerophosphate (SigmaAldrich). Medium was changed every 3 days. On day 24 , cells were fixed using $4 \%$ paraformaldehyde and stained with Alizarin Red S (Sigma-Aldrich).

\section{Differentiation into IPCs}

To induce differentiation into IPCs, hUDSCs were seeded $\left(2.5 \times 10^{5}\right.$ cells/well $)$ in DMEM/F12 (ThermoFisher Scientific), containing 1\% B27 (ThermoFisher Scientific), 1\% N2 (ThermoFisher Scientific), $50 \mathrm{ng} / \mathrm{ml}$ activin A (Peprotech, USA), 2 $\mathrm{mM}$ valproic acid (VPA; Sigma-Aldrich), and 1\% penicillin/streptomycin, in a low-attach 12-well plate (SPL Life Science, Korea) for the first 3 days. On day 4 , the medium was changed to DMEM/F12, containing $1 \%$ B27, 1\% N2, $10 \mathrm{nM}$ exendin-4 (Sigma-Aldrich), 10 $\mathrm{ng} / \mathrm{ml}$ basic fibroblast growth factor (bFGF; Sigma-Aldrich), and 1\% penicillin/streptomycin. On day 7 , the medium was changed to DMEM/F12, containing $1 \%$ B27, $1 \% \quad \mathrm{~N} 2,10 \mathrm{nM}$ exendin-4, 50 $\mathrm{ng} / \mathrm{ml}$ hepatocyte growth factor (HGF; Peprotech), 10 $\mathrm{mM}$ nicotinamide (Sigma-Aldrich), and 1\% penicillin/streptomycin, which was changed every 3 days, up to 15 days.

\section{Glucose-stimulated insulin secretion assay}

After 15 days of IPC differentiation, cells were washed twice with PBS. The cell clusters were incubated with $0.2 \%$ glucose Krebs (KRB) buffer for 1 $\mathrm{h}$ at $37^{\circ} \mathrm{C}$ to synchronize. Thereafter, the clusters were incubated with KRB buffer, containing 3 or $20 \mathrm{mM}$ glucose for $1 \mathrm{~h}$ at $37^{\circ} \mathrm{C}$. The supernatants were collected and diluted 10-fold, and released insulin was measured using an enzyme-linked immunosorbent assay (ELISA) kit, according to the manufacturer's protocol (ALPCO, USA). Insulin content was normalized to protein levels, which was determined using a Pierce BCA Protein Assay kit (ThermoFisher Scientific).

\section{Quantitative real-time polymerase chain reaction (qRT-PCR)}

qRT-PCR was followed the methods of Cha et al.[15], briefly, total RNA was extracted from the cells using RNAiso Plus (Takara Bio Inc., Japan) and cDNA was prepared using the PrimeScript ${ }^{\mathrm{TM}}$ cDNA syn- thesis kit (Takara Bio Inc., Japan) according to the manufacturer's instructions. cDNA samples were analyzed by the SYBR® Premix Ex Taq ${ }^{\mathrm{TM}}$, ROX plus (Takara Bio Inc.) on Bio-Rad cyclers (USA). Gene expression was normalized to the endogenous housekeeping control gene, cyclophillin. Relative expression was calculated for each gene using the $\triangle \triangle \mathrm{CT}$ (where CT is the threshold cycle) method. The primer sequences used are listed in Table 1.

Table 1. RT-PCR primer sequences

\begin{tabular}{lll}
\hline Gene name & & Sequence $5^{\prime}-3^{\prime}$ \\
\hline Pdx1 & Forward & GAA CTT GAC CGA GAG ACA CAT CAA \\
& Reverse & TTG TCC TCC TCC TTT TTC CAC TT \\
Ngn3 & Forward & CGG AGT CGG CGA AAG AAG \\
& Reverse & CGT CCA GTG CCG AGT TGA G \\
Insulin & Forward & GCA GCC TTT GTG AAC CAA CA \\
& Reverse & TTC CCC GCA CAC TAG GTA GAG A \\
Glucagon & Forward & CCC AAG ATT TTG TGC AGT GGT T \\
& Reverse & CAG CAT GTC TCT CAA ATT CAT CGT \\
Cyclophillin B & Forward & TGC CAT CGC CAA GGA GTA G \\
& Reverse & TGC ACA GAC GGT CAC TCA AA \\
\hline
\end{tabular}

\section{Immunocytochemical staining}

On day 15 of IPCs differentiation, clusters were washed with PBS and fixed using $4 \%$ paraformaldehyde in PBS at $4^{\circ} \mathrm{C}$ overnight. The fixed clusters were washed with PBS, then blocked with PBS, containing $1 \%$ BSA and $0.2 \%$ Triton $\mathrm{X}-100$, for $1 \mathrm{~h}$ at room temperature, and incubated overnight with anti-Pdx1 (Millipore, Germany), anti-insulin (Abcam, UK), anti-glucagon (Cell signaling, USA), and anti-cpeptide (R\&D systems, USA) at $4^{\circ} \mathrm{C}$ overnight. Clusters were then stained with a fluorescenceconjugated secondary antibody (Life Technologies, Carlsbad, CA) for $2 \mathrm{~h}$ at room temperature, the nucleus was stained with DAPI $(5 \mu \mathrm{g} / \mathrm{ml})$ for $10 \mathrm{~min}$, mounted with VECTASHIELD (Vector Laboratories, USA), and observed under a confocal microscope (Zeiss, Germany). To evaluate PDX-1, insulin, glucagon and c-peptide, 8 15 clusters were imaged from three independent experiments. Image J program (https://imagej.nih.gov/ij/) was used to quantify the fluorescence intensity.

\section{Statistical analysis}

Statistical analysis was carried out by one-way ANOVA with Bonferroni analysis. Data are presented as means \pm SEM. Values of $p<0.05$ were considered significant.

\section{Results}

\section{Isolation and characterization of hUDSCs}

The hUDSCs isolation procedure is summarized in Figure 1A. The cells obtained from the urine 
samples were cultured and the adherent cells on the plate as a colony were transferred to a 6-well plate. Several different colonies were observed 5 days after initial seeding (Figure 1B). When the colony dissociated and was cultured for several passages, one of the selected clones, hUDSC001.01 showed an elongated morphology (Figure 1C). When we examined whether these cells were contaminated with mycoplasma by PCR, we confirmed that the cells were not contaminated with mycoplasma (Figure 1D).

To examine the expression of stem cell surface markers in hUDSCs, we performed fluorescenceactivated cell sorter (FACS) analysis after staining hUDSCs with antibodies against CD44, CD90, CD105, or SSEA-4. The cells obtained from urine were positive for mesenchymal stem cell antigens, such as CD44, CD90, and CD105. We found that more than $95 \%$ of the cells expressed CD44, and almost all the cells expressed CD90, and CD105, and SSEA-4, but not the endothelial (CD31, CD34) markers (Figure
2A). We next examined the protein expression of selected pluripotent markers in hUDSCs by immunocytochemistry. The protein expression for vimentin and Oct4 was detected, but E-cadherin was not expressed in hUDSCs. In contrast, human adiposederived stem cells (hADSCs), which were used as a positive control, expressed vimentin only (Figure 2B).

\section{Differentiation of hUDSCs to adipocytes and osteocytes}

Stem cells are able to proliferate indefinitely and can differentiate into various types of cells [16]. Therefore, we examined whether the isolated hUDSCs can differentiate into adipocytes and osteocytes. The differentiated adipocytes showed Oil-red-O-stained cells (Figure 3A), suggesting that hUDSCs can differentiate into adipocytes. In addition, osteogenic differentiation was confirmed by Alizarin-positive cells, suggesting that the isolated hUDSCs can differentiate into osteocytes (Figure 3B).
A

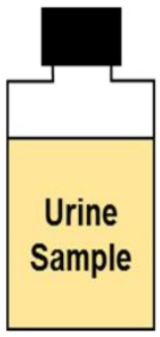

B

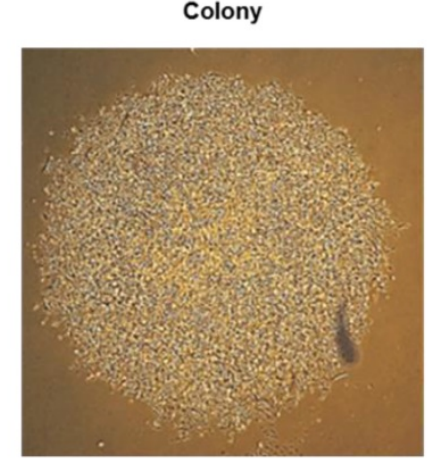

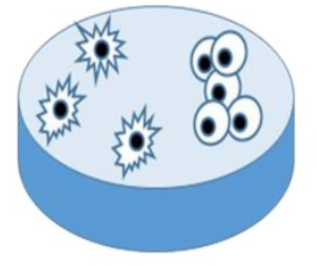
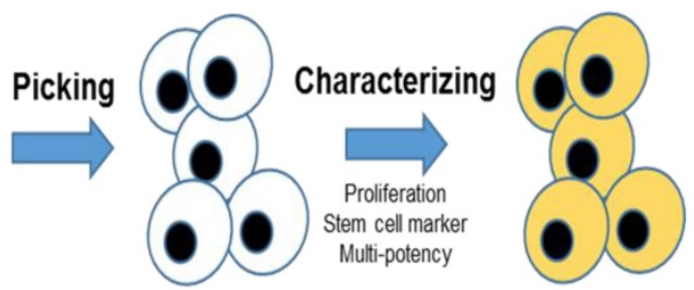

C

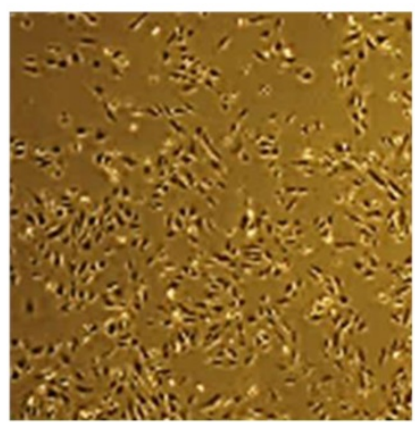

D

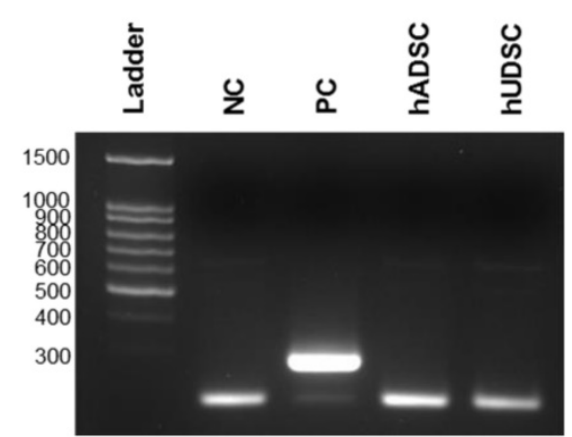

Figure 1. Isolation of hUDSCs. (A) Scheme of isolation of stem cells from human urine. (B) Colony formed at 5 days after plating. (C) Cell morphology. Magnification: 100×. (D) Mycoplasma test by RT-PCR. NC: negative control, PC: positive control. hUDSCs: human urine-derived stem cells, hADSCs: human adipose tissue-derived stem cells. 
A
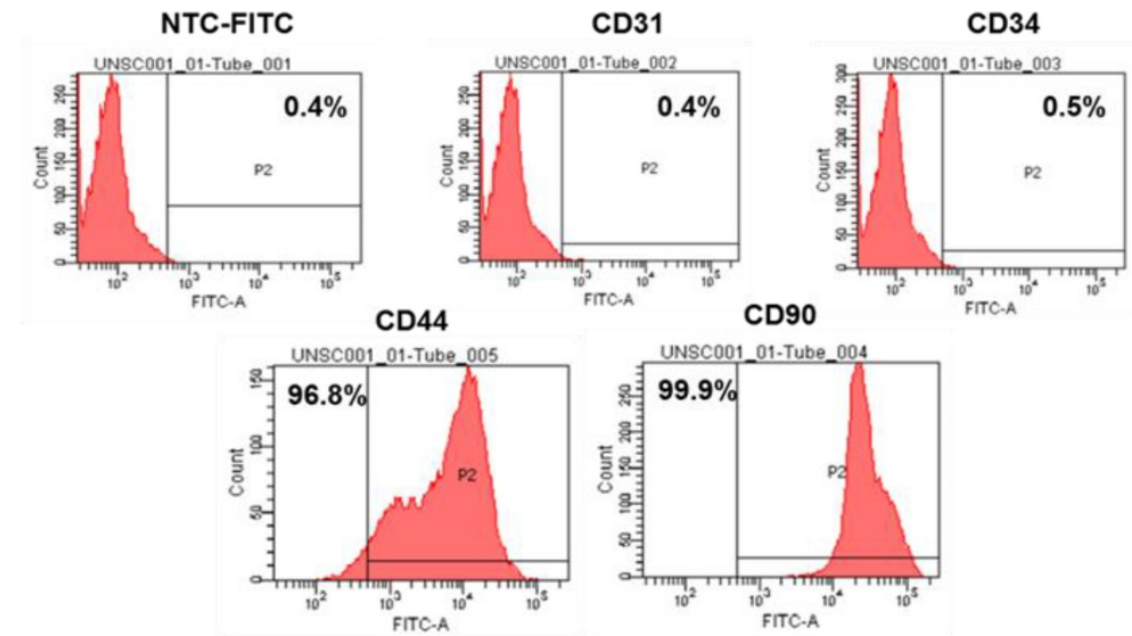

CD105

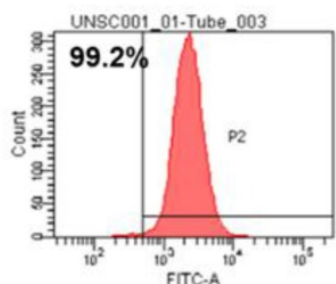

SSEA-4

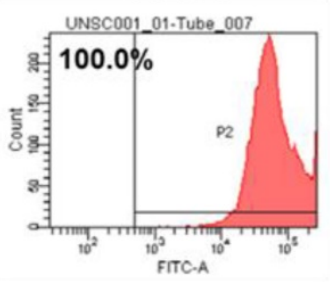

B

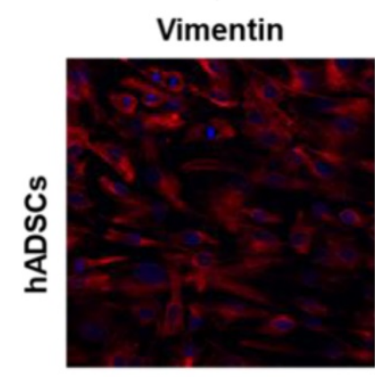

E-cadherin
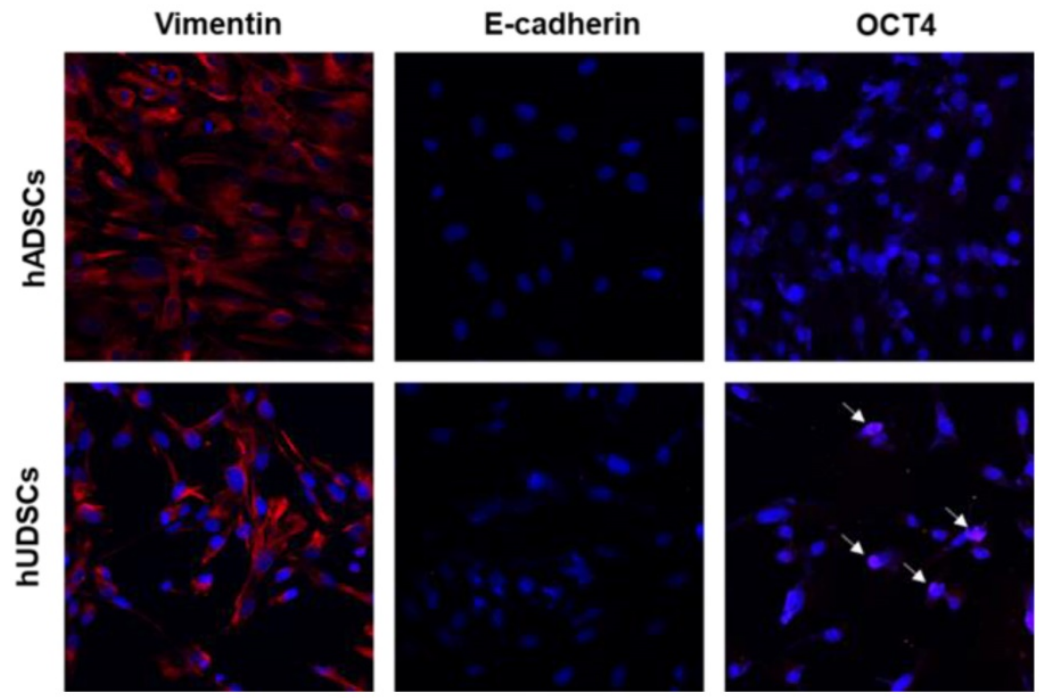

Figure 2. Characterization of hUDSCs for mesenchymal and stem cell markers. (A) The expression of CD31, CD34, CD44, CD90, CD105, and SSEA-4 was assessed by FACS analysis. (B) The expression of E-cadherin and OCT4 was analyzed by immunocytochemistry. hADSCs were used as a positive control. Magnification: $200 \times$.

A

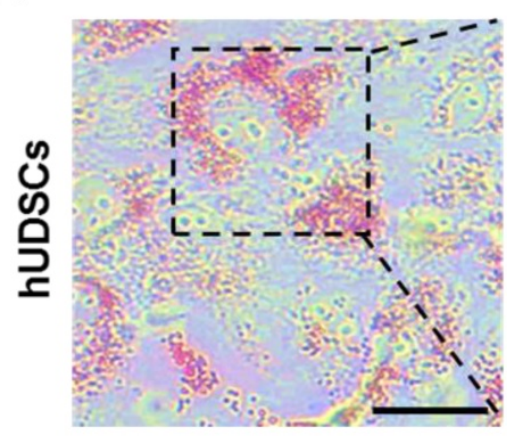

B

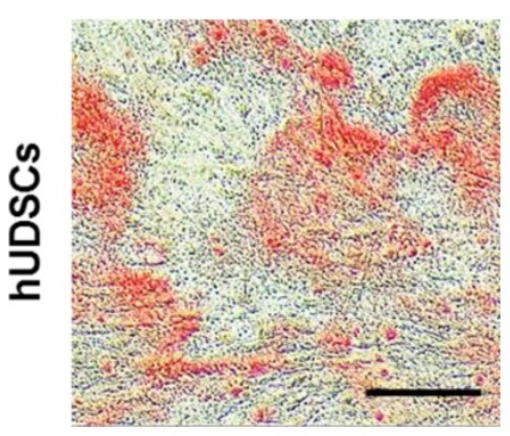

Figure 3. Differentiation of isolated hUDSCs into adipocytes and osteocytes. (A) hUDSCs were differentiated to adipocytes and stained by Oil-red-O. (B) hUDSCs were differentiated to osteocytes and stained by alizarin red S. Scale bars $20 \mu \mathrm{m}$. 
A

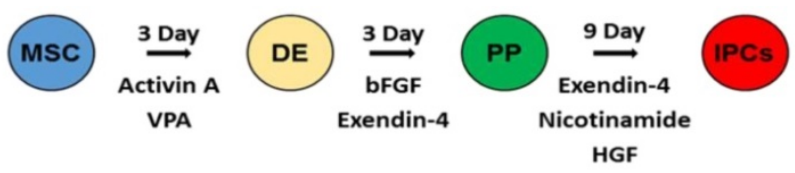

B
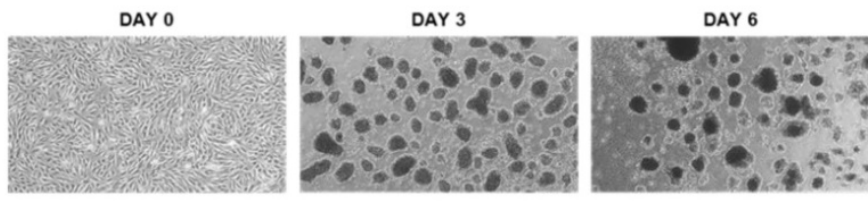

DAY 9 DAY 12

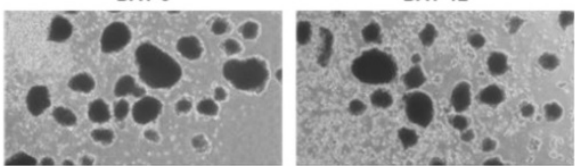

C

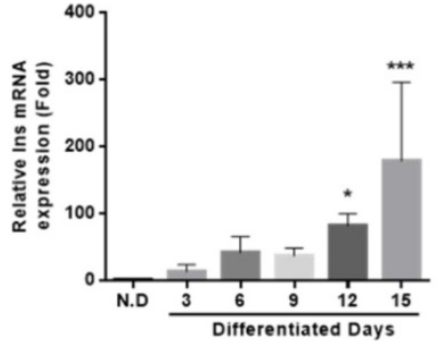

E

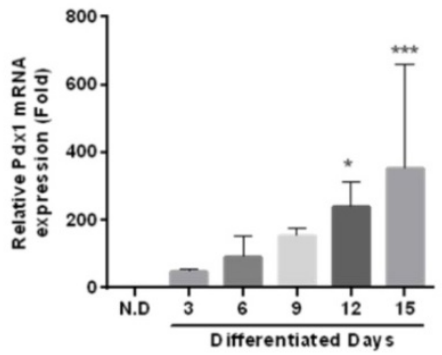

D

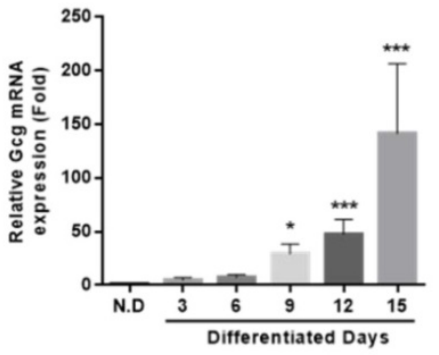

F

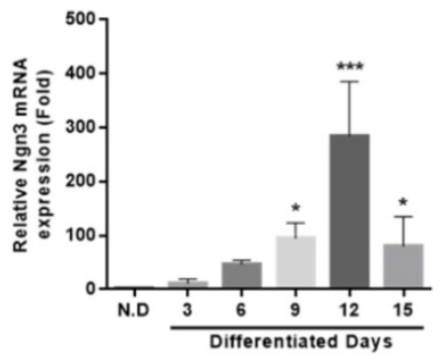

Figure 4. Differentiation of hUDSCs into IPCs. (A) Scheme for the procedure of hUDSC differentiation into IPCs. (B) Morphological changes during differentiation into IPCs. mRNA expression analysis of (C) Ins (insulin), (D) Gcg (glucagon), (E) Pdxl, and (F) Ngn3 was performed by RT-qPCR. N.D: non-differentiation. n=3-4, ${ }^{*} \mathrm{p}<0.05,{ }^{*} * \mathrm{p} p<0.005$.

\section{Differentiation of hUDSCs into IPCs}

To investigate whether the isolated hUDSCs can directly differentiate into IPCs, we differentiated hUDSC to IPCs by a three-step differentiation protocol described in Figure 4A. Within a day, hUDSCs began to form clusters, which became more stable and compact as the differentiation progressed. The morphology of the differentiated IPCs showed smooth and round clusters (Figure 4B). We analyzed mRNA expressions of pancreatic transcription factors, such as pancreatic Pdx1 and Ngn3, and endocrine cell markers (insulin and glucagon) by RT-qPCR. mRNA expression of endocrine hormones, insulin and glucagon, was increased as differentiation progressed, whereas expression in undifferentiated hUDSCs was not detected (Figure 4C, D). mRNA expression of $\mathrm{Pdx1}$ was increased as differentiation progressed (Figure 4E), and Ngn3 mRNA expression increased until day 12 after differentiation, but, the mRNA expression was decreased thereafter (Figure 4F).

\section{Glucose-responsive insulin secretion in IPCs differentiated from hUDSCs}

To confirm that the differentiated cells expressed insulin and glucagon proteins, we performed immunocytochemistry, using anti-insulin, anti-Pdx1, anti-C-peptide, and anti-glucagon antibodies. Differentiated cells were positive for insulin and glucagon. In addition, Pdx1 and C-peptide, a cleavage product of insulin, were co-localized with insulin, suggesting that the differentiated cells clearly produced insulin (Figure 5A). To investigate whether differentiated IPCs could increase insulin secretion in response to glucose, the IPCs were cultured in the presence of low $(3 \mathrm{mM})$ or high glucose $(20 \mathrm{mM})$ concentration and the amount of secreted insulin was measured. We found that insulin secretion was increased about 2-fold in the presence of high glucose compared with that in the presence of low glucose concentration (Figure 5B). 
A
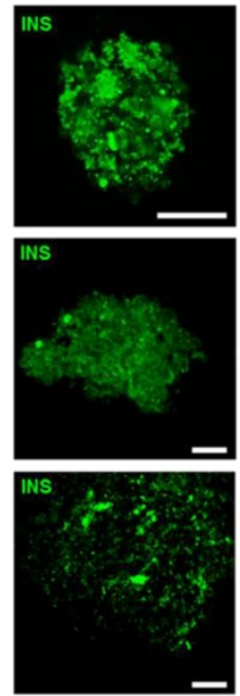
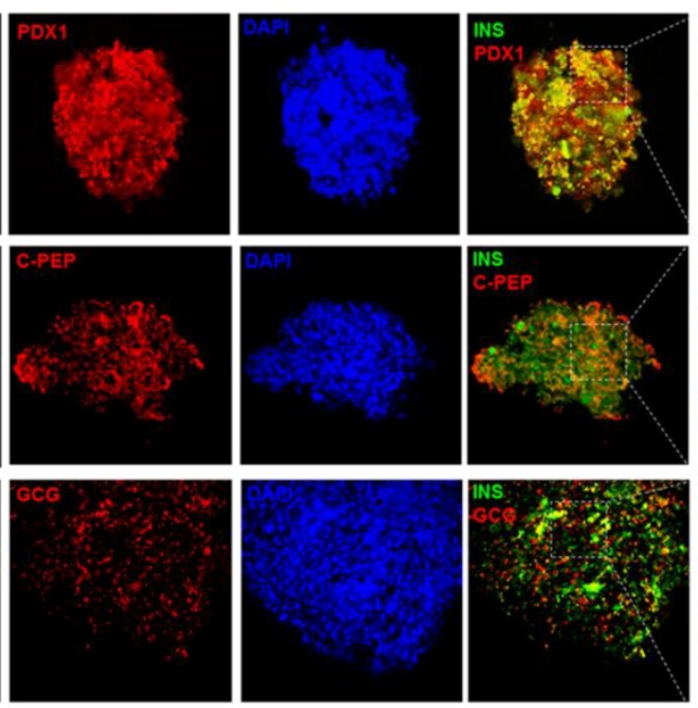
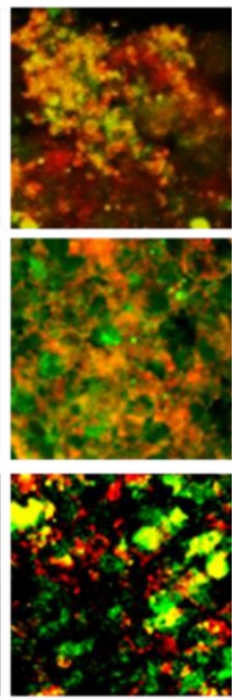

B

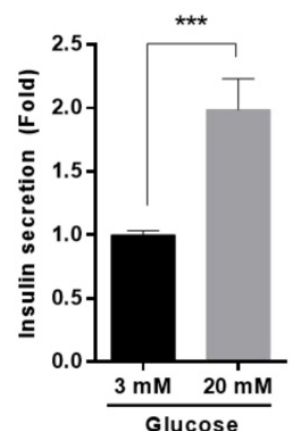

Figure 5. Differentiation IPCs from hUDSCs secreted insulin in response to glucose levels. (A) Differentiated IPC clusters were fixed and stained with anti-INS (green), anti-PDX1 (red), anti-C-PEP (peptide) (Red) or anti-GCG (red) antibodies and observed by confocal microscopy. Blue indicates DAPI (nuclear) staining. Scale bar indicates $50 \mu \mathrm{m}$. (B) Insulin secretion from differentiated IPCs in the presence of $3 \mathrm{mM}$ and 20 mM glucose was analyzed by as described in "Materials and Methods". $\mathrm{n}=3, * * * \mathrm{p}<0.005$.

\section{Discussion}

Type 1 diabetes results from absolute insulin deficiency due to autoimmune-mediated destruction of pancreatic $\beta$-cells [17]. Therefore, daily insulin injections are required for the survival for type 1 diabetic patients. However, exogenous insulin injections cannot tightly regulate insulin levels as endogenous $\beta$-cells do in response to physiological changes in blood glucose levels. Therefore, islet transplantation is considered to be an appropriate therapeutic strategy for the treatment of type 1 diabetes; however, the lack of islet donors is a limitation for this therapy. As an alternative source to solve this limitation, differentiated islet-like cells from stem cells, including mesenchymal stem cells, embryonic stem cells, and induced pluripotent stem cells, have been investigated $[18,19]$.

Mesenchymal stem cells are found in a number of tissues, and may have the ability to transdifferentiate into multiple cell types including adipocytes, osteocytes, myocytes neuronal cells, and islets-like cells [20]. Therefore, the mesenchymal stem cells can be obtained from adipose tissue, bone marrow, muscle, and so on. However, the isolation of stem cells from most tissues requires invasive procedures [21-26].

Stem cell isolation from urine is non-invasive, simple, and easy [10, 11, 27]. In this study, we isolated mesenchymal stem cells from human urine, and characterized and investigated their differentiation potential to IPCs. The isolated hUDSCs expressed CD44, CD90, CD105, and SSEA-4. Cells expressing SSEA-4, an embryonic stem cells marker, have proliferation ability and multi-potency [28]. In addition, it is known that mesenchymal stem cells express CD105, CD90, and CD44, but not CD34, CD31, and CD45 [29]. These results indicate that stem cells isolated from urine may have a mesenchymal stem cell characteristic and multi-potency.

Several stem cell markers, Oct4, sex determining region Y-box2 (Sox)2, Rex1, and Nanog, are needed to maintain self-renewal and the undifferentiated state of stem cells [30-33]. Oct4 was found in oocytes, mouse embryos and germ cells, as well in embryonic stem cells, but not in the differentiated cells [34]. 
Vimentin is also a kind of stem cell marker, particularly expressed in mesenchymal stem cells. The expression of Oct 4 and vimentin was also detected in hUDSCs in our study, whereas the Oct 4 was not detected in hADSCs. These results suggest that hUDSCs display pluripotent stem cell markers and might have differentiation potential.

It was reported that stem cells from urine can differentiate into osteoblast, adipocyte, or skeletal myocyte lineages in vitro $[12,22,27]$. Therefore, we also confirmed that the isolated hUDSCs can differentiate into osteocytes and adipocytes. Direct differentiation of mesenchymal stem cells obtained from different sources into IPCs have been reported $[25,29,35]$. However, it is not known whether hUDSCs can be directly differentiated into IPCs. So, we investigated whether hUDSCs have a potential to directly differentiate into IPCs. When we differentiated hUDSCs to IPCs using combinations of defined factors for $\beta$-cell differentiation as described previously [35], the expression of mRNA and proteins for PDX1 (a pancreatic lineage specific marker) and NGN3 (an endocrine progenitor marker) was observed during the differentiation. In addition, mRNAs and proteins for insulin and glucagon were also detected. These results indicate that isolated hUDSCs have the potential to directly differentiate into IPCs. The most important characteristic for IPCs is the secretion of insulin in response to increase in glucose. Therefore, we examined whether the differentiated IPCs could secrete insulin in response to glucose. We found that the differentiated IPCs increased insulin secretion in the presence of high glucose concentration, compared with low glucose, suggesting that these differentiated IPCs are functional, although the degree of response to glucose was less than the primary islets.

\section{Conclusion}

We demonstrated that the isolated hUDSCs expressed the mesenchymal stem cell markers and can be directly differentiated into IPCs. The differentiated IPCs expressed pancreatic transcription factors, insulin and glucagon. In addition, these IPCs secrete insulin in response to glucose. Although further investigations are needed, our results suggest that hUDSCs might be useful source for cell therapy in type 1 diabetes.

\section{Acknowledgements}

This work was supported by a grant from the Korea Health Technology R\&D Project through the Korea Health Industry Development Institute (KHIDI), funded by the Ministry of Health \& Welfare, Republic of Korea (grant number: HI14C1135) and a grant from Gachon University research fund (grant number: GCU-2018-0309).

\section{Author Contributions}

Y.H. performed the experiments, analyzed data, and wrote the manuscript. S.H.C. designed the study, analyzed data, and wrote the manuscript. Y.H. performed the experiments and analyzed data. A.R.J. performed the experiments and analyzed data. H.S.J. conceived and designed the study, and wrote the manuscript.

\section{Competing Interests}

The authors have declared that no competing interest exists.

\section{References}

1. Yki-Jarvinen $\mathrm{H}$, Koivisto VA. Natural course of insulin resistance in type I diabetes. N Engl J Med 1986; 315(4): 224-230.

2. Peltoniemi P, Yki-Jarvinen H, Oikonen V, Oksanen A, Takala TO, Ronnemaa $\mathrm{T}$, et al. Resistance to exercise-induced increase in glucose uptake during hyperinsulinemia in insulin-resistant skeletal muscle of patients with type 1 diabetes. Diabetes 2001; 50(6): 1371-1377.

3. Docherty K. Growth and development of the islets of Langerhans: implications for the treatment of diabetes mellitus. Curr Opin Pharmacol 2001; 1(6): 641-650.

4. Weir GC, Bonner-Weir S. Islet beta cell mass in diabetes and how it relates to function, birth, and death. Annals of the New York Academy of Sciences 2013; 1281: 92-105.

5. Shapiro AM, Lakey JR, Ryan EA, Korbutt GS, Toth E, Warnock GL, et al. Islet transplantation in seven patients with type 1 diabetes mellitus using a glucocorticoid-free immunosuppressive regimen. N Engl J Med 2000; 343(4): 230-238.

6. Pileggi A, Cobianchi L, Inverardi L, Ricordi C. Overcoming the challenges now limiting islet transplantation: a sequential, integrated approach. Annals of the New York Academy of Sciences 2006; 1079: 383-398.

7. Liew CG, Andrews PW. Stem cell therapy to treat diabetes mellitus. Rev Diabet Stud 2008; 5(4): 203-219.

8. Pagliuca FW, Melton DA. How to make a functional beta-cell. Development 2013; 140(12): 2472-2483

9. Schulz TC, Young HY, Agulnick AD, Babin MJ, Baetge EE, Bang AG, et al. A scalable system for production of functional pancreatic progenitors from human embryonic stem cells. PLoS One 2012; 7(5): e37004.

10. Zhang D, Wei G, Li P, Zhou X, Zhang Y. Urine-derived stem cells: A novel and versatile progenitor source for cell-based therapy and regenerative medicine. Genes Dis 2014; 1(1): 8-17.

11. Zhang Y, McNeill E, Tian H, Soker S, Andersson KE, Yoo JJ, et al. Urine derived cells are a potential source for urological tissue reconstruction. J Urol 2008; 180(5): 2226-2233.

12. Bharadwaj S, Liu G, Shi Y, Wu R, Yang B, He T, et al. Multipotential differentiation of human urine-derived stem cells: potential for therapeutic applications in urology. Stem Cells 2013; 31(9): 1840-1856.

13. Chen L, Li L, Xing F, Peng J, Peng K, Wang Y, et al. Human Urine-Derived Stem Cells: Potential for Cell-Based Therapy of Cartilage Defects. Stem Cells Int 2018; 2018: 4686259.

14. Lv FJ, Tuan RS, Cheung KM, Leung VY. Concise review: the surface markers and identity of human mesenchymal stem cells. Stem Cells 2014; 32(6): 1408-1419.

15. Cha S-H, Hwang $\mathrm{Y}$, Kim K-N, Jun H-S. Palmitate induces nitric oxide production and inflammatory cytokine expression in zebrafish. Fish $\mathcal{E}$ Shellfish Immunology 2018; 79: 163-167.

16. Ilic D, Polak JM. Stem cells in regenerative medicine: introduction. British Medical Bulletin 2011; 98(1): 117-126.

17. Yoon JW, Jun HS. Autoimmune destruction of pancreatic beta cells. American journal of therapeutics 2005; 12(6): 580-591.

18. Kondo $\mathrm{Y}$, Toyoda $\mathrm{T}$, Inagaki $\mathrm{N}$, Osafune $\mathrm{K}$. iPSC technology-based regenerative therapy for diabetes. Journal of diabetes investigation 2018; 9(2): 234-243.

19. Pan G, Mu Y, Hou L, Liu J. Examining the therapeutic potential of various stem cell sources for differentiation into insulin-producing cells to treat diabetes. Annales d'Endocrinologie 2018.

20. Ullah I, Subbarao RB, Rho GJ. Human mesenchymal stem cells - current trends and future prospective. Bioscience reports 2015; 35(2): e00191.

21. Okura H, Komoda H, Fumimoto Y, Lee CM, Nishida T, Sawa Y, et al. Transdifferentiation of human adipose tissue-derived stromal cells into 
insulin-producing clusters. Journal of artificial organs : the official journal of the Japanese Society for Artificial Organs 2009; 12(2): 123-130.

22. Kang HS, Choi SH, Kim BS, Choi JY, Park GB, Kwon TG, et al. Advanced Properties of Urine Derived Stem Cells Compared to Adipose Tissue Derived Stem Cells in Terms of Cell Proliferation, Immune Modulation and Multi Differentiation. J Korean Med Sci 2015; 30(12): 1764-1776.

23. Marappagounder D, Somasundaram I, Dorairaj S, Sankaran RJ. Differentiation of mesenchymal stem cells derived from human bone marrow and subcutaneous adipose tissue into pancreatic islet-like clusters in vitro. Cellular E molecular biology letters 2013; 18(1): 75-88.

24. Lavon N, Yanuka O, Benvenisty N. The effect of overexpression of Pdx1 and Foxa2 on the differentiation of human embryonic stem cells into pancreatic cells. Stem Cells 2006; 24(8): 1923-1930.

25. Pagliuca FW, Millman JR, Gurtler M, Segel M, Van Dervort A, Ryu JH, et al. Generation of functional human pancreatic beta cells in vitro. Cell 2014; 159(2): $428-439$

26. Cooper O, Seo H, Andrabi S, Guardia-Laguarta C, Graziotto I, Sundberg M, et al. Pharmacological rescue of mitochondrial deficits in iPSC-derived neural cells from patients with familial Parkinson's disease. Science translational medicine 2012; 4(141): 141ra190.

27. Bharadwaj S, Liu G, Shi Y, Markert C, Andersson KE, Atala A, et al. Characterization of urine-derived stem cells obtained from upper urinary tract for use in cell-based urological tissue engineering. Tissue Eng Part A 2011; 17(15-16): 2123-2132

28. Rosada C, Justesen J, Melsvik D, Ebbesen P, Kassem M. The human umbilical cord blood: a potential source for osteoblast progenitor cells. Calcif Tissue Int 2003; 72(2): 135-142.

29. Xin Y, Jiang X, Wang Y, Su X, Sun M, Zhang L, et al. Insulin-Producing Cells Differentiated from Human Bone Marrow Mesenchymal Stem Cells In Vitro Ameliorate Streptozotocin-Induced Diabetic Hyperglycemia. PLoS One 2016; 11(1): e0145838.

30. Chambers I, Colby D, Robertson M, Nichols J, Lee S, Tweedie S, et al. Functional expression cloning of Nanog, a pluripotency sustaining factor in embryonic stem cells. Cell 2003; 113(5): 643-655.

31. Pan G, Li I, Zhou Y, Zheng H, Pei D. A negative feedback loop of transcription factors that controls stem cell pluripotency and self-renewal. FASEB journal : official publication of the Federation of American Societies for Experimental Biology 2006; 20(10): 1730-1732

32. Loh $\mathrm{YH}, \mathrm{Wu} \mathrm{Q}$, Chew JL, Vega VB, Zhang $\mathrm{W}$, Chen $\mathrm{X}$, et al. The Oct4 and Nanog transcription network regulates pluripotency in mouse embryonic stem cells. Nature genetics 2006; 38(4): 431-440.

33. Wang J, Rao S, Chu J, Shen X, Levasseur DN, Theunissen TW, et al. A protein interaction network for pluripotency of embryonic stem cells. Nature 2006; 444(7117): 364-368

34. Chang C-C, Tsai IL, Kuo KK, Wang KH, Chiang C-H, Kao AP, et al. Expression of Oct-4, alpha fetoprotein and vimentin, and lack of gap-junctional intercellular communication (GJIC) as common phenotypes for human adult liver stem cells and hepatoma cells. Cancer Research 2004; 64(7 Supplement): 642-642.

35. Dao LT, Park EY, Hwang OK, Cha JY, Jun HS. Differentiation potential and profile of nuclear receptor expression during expanded culture of human adipose tissue-derived stem cells reveals PPARgamma as an important regulator of Oct4 expression. Stem cells and development 2014; 23(1): 24-33. 